\title{
Ecological Vulnerability Evaluation in West China: Evaluate Vulnerability and Its Synergy Degree with Government Performance
}

\author{
Huping Shang ${ }^{1}$, Qingying Han ${ }^{2}$, Yan Li ${ }^{3 *}$ \\ ${ }^{1}$ School of Political Science and Public Administration, Soochow University, Suzhou, CHINA PR \\ ${ }^{2}$ Zhou Enlai School of Government, Nankai University, Tianjin CHINA PR \\ ${ }^{3}$ The Humanities and Social Sciences Department, Dalian University of Technology, Dalian, CHINA PR
}

Received 12 June 2017 • Revised 3 September 2017 • Accepted 27 September 2017

\begin{abstract}
In this paper, a developed PSR model based on Chinese context is established to deal with the ecological vulnerabilities in western China. Judged by the model, we find that the essential way to pre-control the vulnerabilities is to evaluate it. Then a pre-control concept model is developed to evaluate and intervene the vulnerabilities. To carry out the pre-control model, we could use a series of evaluation equations to measure the single vulnerabilities, overall vulnerabilities, vulnerability changing trends, and the synergy degrees between the western ecological vulnerabilities and the performances of the local governments. Under the guidance of the evaluation results, the local governments and other organizations could choose the proper pre-control measures from the strategy matrix to respond to varied ecological vulnerabilities.
\end{abstract}

Keywords: western China, ecological vulnerability, evaluation, local government performance, pre-control

\section{INTRODUCTION}

In recent years, the natural crises caused by the ecological vulnerabilities directly or indirectly have occurred more and more frequently in western China in the past years.

Yushu County in Qinghai Province had two earthquakes in the morning of April 14, 2010, making 2220 people killed and 70 others missing. A population of 897.8 thousand people in the 12 counties in Chongqing suffered from the disasters of strong winds, hail, and heavy rain in the same year. From July 18, 2010, heavy rains in the upper reaches of the Yangtze River made the water level rising up to 25.66 meters in Guang'an Canal River in Sichuan Province. It was the biggest floods occurred in Guang' an since 1847 (Ye, 2010). Since then, the disaster triggered a gradual expansion of floods. In the evening of July 28, heavy rain touched off landslides and floods in Qilian Mountains, causing an economic loss of 31,242,500 yuan. In August, the lasting strong rains in Gannan Tibetan Autonomous Prefecture gave rise to the devastating mudslides that killed 1435 lives and made 330 lives missing. Almost at the same time, Xincheng torrential mudslides in Sichuan occurred, which affected 57,600 hundred thousand people with a direct economic loss of about 6.89 billion yuan. Yingxiu town was completely ruined by a series of floods (Zhou, 2010). Till now, the ecological crises caused by the ecological vulnerabilities are still frequent in western China (Shang, 2011).

Although we mentioned the crises in these years, they have actually become common phenomena since the China's economy began to thriving. Traced back a few years, the western ecological crises due to the ecological vulnerabilities have already drawn international astonishments. Snow and ice storms in southwest led 118,742,000 hectares of crops to low yield, and it made a direct economy loss of 151.65 billion. So far, the arid mountains and plateaus in western China have resulted in landslides during these years, which lead to continuous low intensity earthquakes. The earthquakes damaged 417 counties in the provinces of Sichuan, Gansu, Shaanxi, Chongqing and the affected population reached 46,256,000 and the direct economic losses amounted to 852,309 billion yuan (Yang, 2010). The constant high temperature in most parts of Xinjiang made $18,676,000$ hectares of natural grassland 


\section{Contribution of this paper to the literature}

- We could use "big data" technologies and data mining skills to stride over the gap between these scattered databases to build a "western China ecological vulnerability evaluation database" that is composed by a series of sub-databases.

- We should establish a sustainable developing value in western China. Under the new value, the local governments are needed to treat economy developing and ecology protecting equally.

- In the evaluation of the ecological vulnerability, the indicator system is the key to open the vulnerability state of the "ecological black box".

- To some extent, the quality of ecological vulnerability evaluation depends on the quality of evidence data.

- The effective path to implement the vulnerability evaluation could be explored. This involves choosing the proper evaluating cites, deciding the evaluating time, and determining the evaluation flows.

severely drought. The Severe droughts in Ningxia brought 987,000 farmers into despair statuses because they almost lost all their crops. Heavy snowfall in Tibet affected 100,000 people and caused a great part of them lost their houses (NDRCMCA, 2009). There are even more crises caused by ecological vulnerabilities in western China, but we mentioned only a few.

Currently, the ecological rises caused by the ecological vulnerabilities in west China are still spreading, and they even have the trends to expand to other regions (Kai \& Haokai, 2016). The governments of varied levels still have no effective responding measures till now. Both the local governments and the central government take the fire-fighting policies to deal with the ecological vulnerabilities: when varied vulnerabilities have already burst into ecological crises, they cope with them passively and ineffectively (Shang, 2011). So far, the effective means of prevention still has not appeared. The Environmental Channel of People's Daily Online invited the top experts in China to explore the applicable methods to get out of the dilemma in January 2014, but they found no efficient ways. This calls on us to probe into the problem and find the efficient pre-control methods to step out of the plights.

\section{LITERATURE REVIEW}

The academics have made their effort to solve the problems caused by ecological vulnerabilities in western China. Williams (1997) found by the anthropological methods that the farmers in Horqin Desert had very strong feelings on the sands and deserts, so the local governments should encourage the localities to take part in the activities of protecting the deserts. Zhao and Shao (2006) made an investigation on the ecological fragmentation, and they prompted a suggestion to recover the ecosystem by planting proper plants. Yuan et al (2000) evaluated the ecology damages in large-scale development of China's western region. He pointed out that the developing ruined the ecology, and the developing-protecting policy should be carried out so as to protect the ecology. Uchida, $\mathrm{Xu}$ and Rozelle (2005) found that the sampled farmers were satisfied with the ecology restoration projects implemented by the local governments. He put forward a proposal to move onwards these projects. While Bennett et al (2008) didn't agree with Uchida et al's findings; he reminded that the sampled farmers were selected on political purpose by the local governments. Bennett et al's findings doubted that the ecology restoration projects might be reformed so as to restore the environments effectively. Zhang et al (2006) analyzed the Chinese western semi arid deserts by the remote sensing spectrum approach. They uncovered the hidden actuality that these deserts are losing carbons, and preventing the ecology remedying the lost carbons, which led to ecological vulnerability. Melick, Yang and Xu (2007) suggested that urbanization should be accelerated with forest protecting in Tibet. Pimentel et al (2007) and Prokop, et al (2016) explored the relation between the population growth and environmental deterioration in western China. He proposed that the coordinated development strategy between population and environment should be implemented. Wang et al (2007) and Bennett, et al (2008) classified the China's ecological vulnerability restoration projects. They found that whatever the projects were they hadn't been carried out well evaluated by the restoration aims. New and Xie (2008), Jim and Chen (2009) predicted the effects of the Three Gorges project on the ecological vulnerability, and they thought the "great project" might result in ecological tragedies unless some intervention measures were taken. Tilt (2008) and Squires et al (2010) probed into the actuation of the western economic and social development on the ecological vulnerabilities. They proposed that it was the economic and social developing that caused the vulnerabilities, and getting out of the morass depended on sustainable development policies. Li et al (2010) detected loess plateau soil erosion in western china by the magneto motive force. His findings showed that the soil erosion could result in ecology vulnerability, and protecting the soil actually meant protecting the ecology. Michalk (2010) designed a set of strategies to overcome the present shortcomings of grassland livestock system in Chinese west regions. Wong et al (2010) and Liu et al (2009) studied vegetation integrity in Northwest China, they found the possible way to improve the vegetation in the area is reforesting. Yamaguchi (2011) found that although the damages to the ecology caused by traditional 


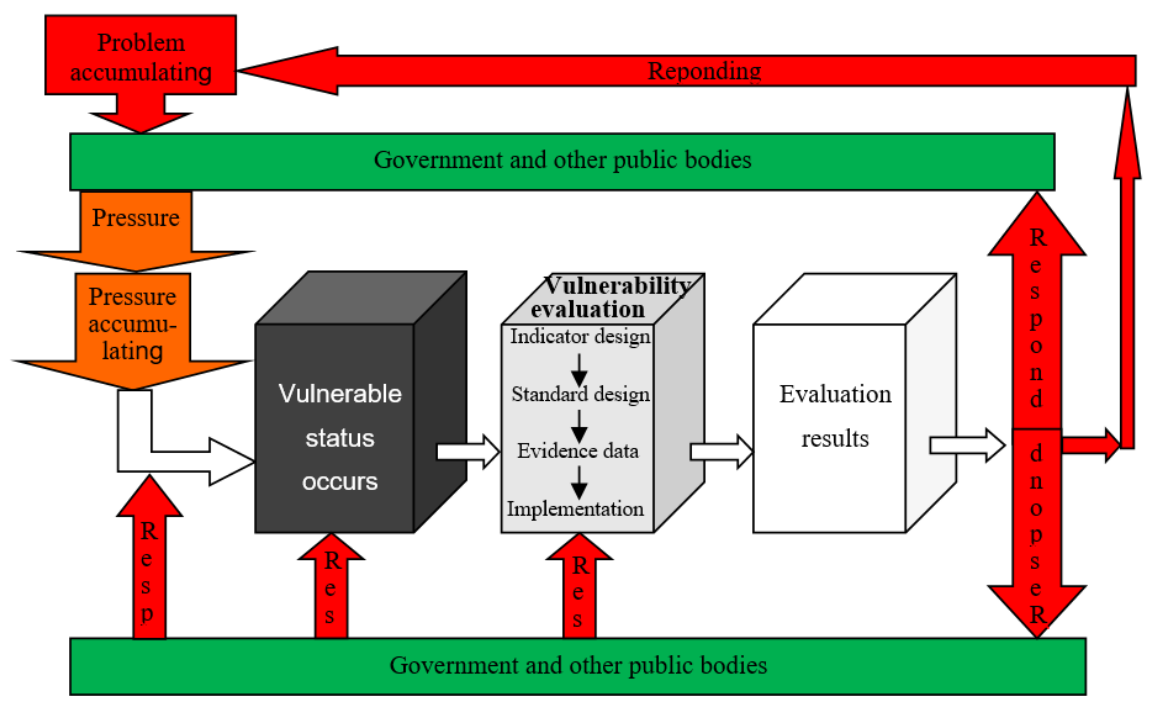

Figure 1. The Pressure-State-Response Model in West China

husbandry were diminishing, the harms caused by new husbandry were increasing. In his opinion, regulating on new husbandry should be taken to conserve the environments.

Although the researchers have already made great progresses in overcoming the western problems caused by varied ecological vulnerabilities, they pay no enough attention to pre-control the problems by evaluating the vulnerabilities. Magretta (1999) has emphasized that if no evaluation is made, there will be no efficient management. Due to the lack of evaluation to the western ecological vulnerabilities, especially the timely evaluation, the central and local governments cannot cope with the increasing ecological disasters in western China effectively. In fact, evaluation always has the pre-control function (Weihrich \& Koontz, 1998). In this sense, evaluating the ecological vulnerability in west China could pre-control the ecological problems generated by varied vulnerabilities. As a pre-control tool, evaluation could keep the ecological problems from expanding to other regions and could help the central and local governments to take some coping tactics to handle the wicked problems to the point. Unfortunately, neither the theorists nor the practitioners made no efficient efforts in evaluating the China' west ecology vulnerabilities. We want to address this gap by making out the mechanics of how the western vulnerabilities occur and develop a series of vulnerability evaluation models and methods to pre-control the ecological problems in western China.

\section{OCCURRENCE AND RESPONSE MECHANISMS OF THE ECOLOGICAL VULNERABILITIES IN WESTERN CHINA}

The PSR (Pressure-State-Response) model proposed by Rapport et al. $(1979 ; 1998)$ could explain the occurrence and response mechanisms of the ecological vulnerabilities well and draw international prestige since the Organization for Economic Cooperation and Development (OECD) and the United Nations Environment Programme (UNEP) advocated to use it throughout the world. In spite of that, the PSR is meeting gradual challenges in coping with the more and more severe ecological vulnerabilities all over the world ( $\mathrm{Zhang}$, Su, \& Zhang, 2011). In order to uncover how the SPR model works in China's western ecological vulnerabilities, we collected 99 cases that deal with varied ecological vulnerabilities in the west China. The cases covered the reaction process from occurring to coping with (controlling), from which we could summarize the Pressure-State-Response rules. These cases consisted of different vulnerabilities in western China, such as the Wenchuan earthquakes, Qilian mudslides, Guang'an super-heavy rain, Xinjiang lingering droughts, southwest heavy snow, Panzhihua-Huili earthquakes, and Tibet heavy snowfall. We put all the cases into the PSR model and analyzed Pressure-StateResponse rule of each case. Processed the data of each case by SPSS 19.5, we draw a new Pressure-State-Response model that indicates the mechanism of how the vulnerabilities occur, how to evaluate them and how to respond to them according to the evaluation results based on China's west context (Shang, 2011) (See Figure 1).

As shown in Figure 1, the new model could explain the mechanism of how the vulnerabilities in western China occur, and how they would be responded.

Firstly, the ecological problems such as groundwater overexploitation, excessive felling of trees, the surge in population density, arable land decreasing, forest coverage reducing, frequent mudslides gradually accumulate to form ecological "pressures". 
Secondly, as the ecological pressures grow and grow, the ecological "vulnerability status occurs".

Thirdly, although the vulnerability status occurs, it is in fact a "black box" for the governments and other public bodies to deal with. The "black box" means there is no enough accurate information for the society, governments and other bodies to cope with the vulnerabilities. If varied bodies hastily step into the "black box", they will respond impertinently like the blind men patting an elephant.

Fourthly, in order to make out the real situation of "Vulnerability Status" and transfer the "black box" to the "white box", we have to evaluate the vulnerable state. The complete scientific evaluation process includes at least four steps: designing the evaluation indicators, designing the evaluation standards, acquiring the evidence data, and implementing the vulnerability evaluation. In fact, the process of evaluation is to make the "black box" become clearer and clearer, and this is a process of de-blackening. In this course, with the evaluation goes on, we have more and more information about what kind and how serious the status of vulnerabilities are. When the evaluation ends, the evaluation results will make the black-box transparent, and a "white box" appears.

Fifthly, the governments and other bodies could respond according to the evaluation results to pre-control the vulnerabilities in west China. The evaluation results could provide clues to understand the reasons of the vulnerabilities and how to respond to them targetedly.

Finally, as the appearance of the "white box", the governments and other bodies must cope with the vulnerabilities timely and efficiently just like the police respond to terror attacks or terror crisis. The red color in Figure 1 represents the urgency and timeliness to deal with the vulnerabilities and ecological crises. Guided by the evaluation results, the governments and other bodies could respond accordingly. This makes the ecological vulnerabilities become easing or even could be solved. So there may appear health ecological statuses the people have long expected, which are shown in Figure 1 by the green color.

In all the aspects, ecological vulnerability evaluation is the most critical. Because only through the evaluation, the society, government and other bodies could understand the specific status, strength and incentives of the vulnerability, and make targeted interventions and crisis management. As shown in Figure 1, all aspects of targeted interventions are dependent on the guidance of the evaluation results; however, the feed-forward prevention interventions before the evaluation belong to the blind-man-touching-an-elephant style. Although we welcome such feed-forward interventions, but it is after all lack of reliability and full of recklessness. Truly effective intervention is the targeted feedback intervention after obtaining the evaluation results. The results could serve as a pre-control guidance.

\section{PRE-CONTROL THE ECOLOGICAL VULNERABILITIES IN WESTERN CHINA BY EVALUATION}

The current researches pay no enough attention to pre-control ecological vulnerabilities in western China by evaluating them (Shang, 2011). Namely, the researchers seldom probe into the evaluation work such as designing the evaluation indicators, deciding the evaluation standards, selecting the evidence data, implementing the evaluation, and using the evaluation results to intervene the ecological problems. This makes us unable to target the preventive coping before the occurrence of vulnerabilities, to target the timely intervention during the vulnerability process, and to implement the feedback-control intervention after it. In the light of this circumstance, under the guidance of the new PRS model, we propose a pre-control model serving as concept model to evaluate and pre-control the vulnerabilities in west by the model, we could pre-control the vulnerabilities in west China.

Specifically, the pre-control process follows the flow: Sort the ecological vulnerability data of west China, and construct the vulnerability database, data marts and data warehouses $\rightarrow$ Mine the evaluation indicators by clustering method $\rightarrow$ Evaluate the vulnerability statuses $\rightarrow$ Evaluate the synergy degrees between the western ecology vulnerability and the performance of local governments $\rightarrow$ Return the evaluation results to the vulnerability data warehouse to constitute the "vulnerability result data mart" and "synergy degree mart" $\rightarrow$ Detect the relations between the two evaluation results (vulnerability results \& synergy degree results) $\rightarrow$ Make out the intervention measures for the governments and other bodies (see Figure 2). 


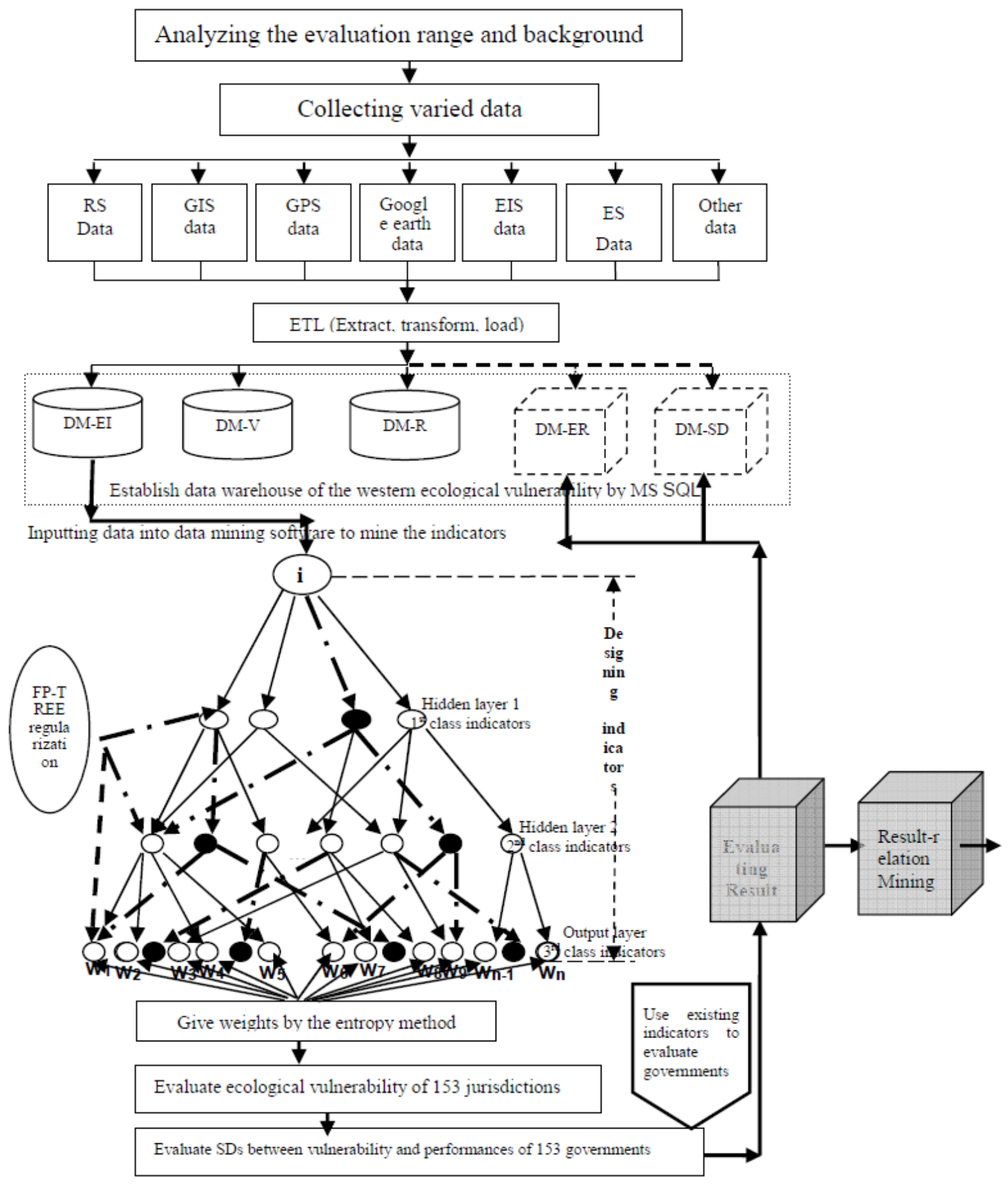

Figure 2. Flow to Pre-control Ecological Vulnerability by Evaluation in Western China

\section{Collecting Data from Varied Sources and Constructing the Western Ecology Vulnerability Database, Data Marts and Data Warehouses}

"West China" covers about $71 \%$ of the country's total area and about $29 \%$ of the country's total population. But the whole district is suffering from the ecology problems caused by ecological vulnerabilities (Wang, Lu, Fang \& Shen, 2007). In the pre-control process, we first need to sort varied data related to ecological vulnerabilities in the "western China". The data can be collected from the different databases and sources such as remote sensing database (RS), geographic information systems (GIS), global positioning data (GPS), GOOGLEEARTH, environmental simulation systems (EIS), environmental yearbook (EYB), climate yearbook (CYB), geological 


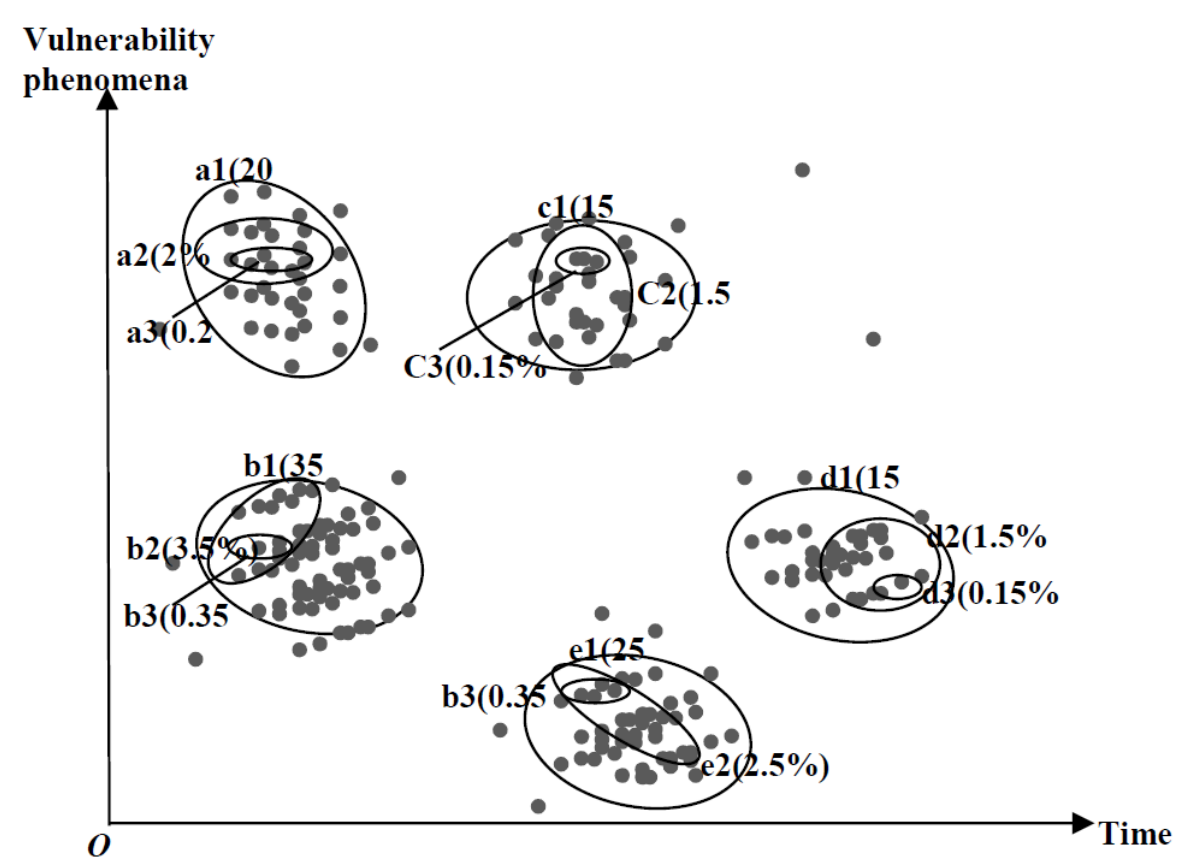

Figure 3. Logic of Cluster-mining Vulnerability evaluation indicators

database (GDB), and ecological footprint data (EFD). Besides, we could survey the local people to get some data on how the ecology and environment influence their lives and how they see the ecology and environment changes.

By inputting the organized and sorted data into the software, i.e., MS SQL SERVER or ORACAL, a data warehouse of the western ecology vulnerabilities (DW-WEV) could be built after ETL (extract, transform, load) processing. DW-WEV consists of a data mart of evaluation indicators (DM-EI), a data mart of vulnerabilities (DM$\mathrm{V})$, and a data mart of responding (DM-R). In addition, after we get the results of the evaluation, we will add a data mart of evaluation results (DM-ER) and a data mart of the synergy degrees between the western ecology vulnerability and the performance of local governments (DM-SD) to DW-WEV. At last, DW- WEV will be made up of 5 data marts.

\section{Cluster-Mining of the Evaluation Indicators of the Western Ecology Vulnerability}

Essentially, the selecting of the evaluation indicators is actually a process of weighting and clustering indexes layer by layer (Shang, 2013). The two coordinate axes-vulnerability phenomena and time form a variable space. Researchers or practitioners need to recognize explicit, semi-explicit, or implicit vulnerability phenomena in the space, then cluster them layer by layer and set their common attribute as name of a new indicator (see Figure 3) (Shang, 2013). Generally, ecological vulnerabilities could be clustered and form several first-class indicators (a1, b1, c1, d1, e1 in Figure 1) according to the distribution of explicit, semi-explicit, or implicit vulnerability phenomena appear in different periods (scattering points in Figure 3). All the first-class indicators should be put weight on the condition that the sum of their weights are equal to $1(100 \%)$. In this way, ecological vulnerabilities that need to be evaluated are concentrated on five aspects, in other words, vulnerabilities of these five aspects would represent all ecology vulnerabilities, hence evaluation of these five aspects approximately equates with evaluation of the total vulnerabilities. After the first-class clustering, we can continue to cluster the second-class, third-class or even fourth-class, fifth-class indicators according to the accuracy of the evaluation. Indicators of each class should be weighted on the premise that the sum of their weights equals the weight of their corresponding first-class indicator. Theoretically, hierarchical clustering is endless; however, we generally cluster to the third class in practice (Hartigan, 1975). Figure 1 just marks second-class and third-class indexes, namely a2, a3, b2, b3, etc.

The first need of clustering the indicators of vulnerability evaluation in the western China is to obtain a set of draft indicators. Specific neural networks, decision trees and other cluster mining methods can be applied to do the clustering job. As the draft indicators are too extensive and "over-fitting", there still have "noises" that need the further wiping off. The association rules, such as FP-TREE, APPRIOR, etc. can be performed to remove the unrelated "noise" indicators. As the "noises" are removed, we could go to the next step of giving weights to the indicators. Among the methods of determining the indicator weights, the entropy method does not require any assumption on the patterns of data distribution, which could efficiently determine the indicator weights among all kinds of heterogeneous ecological vulnerability data in west China. It should be emphasized that we use 
information entropy determine the weights of the third-class indicators, and the weights of the second-class and the first-class indicators could be automatically produced. The specific process is as follows.

In accordance with the information theory, the information entropy of the third level indicators could be determined as $H(i)=-\sum_{n} \rho\left(i_{n}\right) \ln \rho\left(i_{n}\right)$. In the equation, $i$ stands for indicators, $\rho\left(i_{n}\right) \in[0,1], \sum_{n} \rho\left(i_{n}\right)=1$.

At first, suppose the number of evaluating objects as $m$, the number of measuring indicators as $n$ to form the data matrix of the indicators as $I=\left(i_{\alpha \beta}\right)_{m \times n}$. For an indicator $i_{\alpha}$, the larger the gap of the indicator $i_{\alpha \beta}$, the greater the amount of information provided by the indicator, the heavier the weight will be. Conversely, the smaller the gap, the lighter the weight. If the values of indicators are all equal, it does not work in the comprehensive evaluation.

Secondly, the indicator needs to be converted to the proportion form $\rho_{\alpha \beta}$ as equation (1):

$$
\rho_{\alpha \beta}=\frac{i_{\alpha \beta}}{\sum_{\alpha=1}^{m} i_{\alpha \beta}},(\alpha=1,2, \ldots, m ; \beta=1,2, \ldots, n)
$$

Then define the $\beta$ indicator as the entropy equation (2)

$$
H_{\beta}=-k \sum_{\beta=1}^{m} \rho_{\alpha \beta} \ln \rho_{\alpha \beta},(\beta=1,2, \ldots, n)
$$

Wherein, $k=\frac{1}{\ln m}$, the constant $\mathrm{k}$ ensures that each proportion of $\beta$ indicator is equal to $\left(k=\frac{1}{m}\right)$ and meet $H_{\beta}=$ 1. Then, this indicator does not provide any information and has no effect on the comprehensive measurement. It is also assumed in the equation that $\rho_{\alpha \beta}=0$, then $\ln \rho_{\alpha \beta}=0$, which ensures $H_{\beta} \in[0,1]$.

Finally, the definition of entropy $w_{\delta \beta}$ of $\beta$ indicator as equation (3),

$$
w_{\delta \beta}=\frac{1-H_{\beta}}{\sum_{\beta=1}^{n} 1-H_{\beta}}=\frac{1-H_{\beta}}{n-\sum_{\beta=1}^{n} H_{\beta}},(\beta=1,2, \ldots, n)
$$

Among them, $w_{\delta \beta} \in[0,1] ; \sum_{\beta=1}^{n} w_{\delta \beta}=1$. After these three stages, all the third-class indicators will have weights.

\section{Evaluating the Ecological Vulnerabilities in Western China in a Certain Period}

As the indicators have been selected and given weights, we could begin to implement evaluations. In fact, "ecological vulnerability" is a general concept. It specifically includes single ecological vulnerability, overall ecological vulnerability. The single ecological vulnerability is caused by single ecological problems, such as soil erosion, forest destruction, and drought. The overall ecological vulnerability is the integrated ecological vulnerabilities comprehensively caused by multiple single-ecological-vulnerability in a certain time. These two aspects must be involved in the evaluation of western ecological vulnerabilities. Furthermore, as a pre-control tool, the evaluation must include evaluating to the changing trend of ecological vulnerabilities and synergy degrees between the western ecological vulnerabilities and the local governments' performances. To some extent, how the local governments see the ecological vulnerabilities and how they deal with them always determine which directions the vulnerabilities go.

\section{Evaluating the single ecological vulnerability}

Every evaluation indicator could measure a certain kind of vulnerability, and this is a single ecological vulnerability. Because any single ecological vulnerability could lead to ecological crisis needing quick intervention, we should pay enough attention to use every indicator to evaluate such single vulnerability. As a matter of fact, a plenty of ecological crises occurred in western China were caused by a single vulnerability. For example, landsides in Zhouqu caused serious crisis; lasting droughts in Yunnan resulted in great losses; high winds in Xinjiang led to serious effects both in people and animals. The objective to evaluate the single vulnerability aims to avoid the ecological crisis, but the crisis is touched off only when the single vulnerability reaches the "threshold value". So, we must evaluate by the single indicator if the vulnerability come near the "threshold value". When the indicator shows that the single vulnerability reaches the "threshold value", the evaluation of the overall vulnerability temporarily gives way to the individual ecological crisis, shown in equation (4). Because the indicator $i$ reached the "threshold value" (The "threshold value" of crisis is determined by the international standards of ecological vulnerabilities and the historical data of the western vulnerabilities), at this point, the vulnerability value $\mathrm{V}$ equals to the vulnerability value $v_{i}$ of this indicator. It represents the arrival of a single ecological crisis and the need for government intervention in a timely manner. This is also the management basis for the decision-making in ecological crisis.

$$
V=v_{i},\left(i \in R^{+}, n \in R^{+}\right)
$$




\section{Evaluating the overall ecological vulnerability}

Although the ecological crisis triggered by the single ecological vulnerability exists, it is not the normality. The normality lies in that vulnerabilities generally exist to some extent, but they do not always cause crises. In order to know such vulnerabilities well, we need to conduct a comprehensive evaluation in the periodic intervals (usually a year). This requires us to apply all the indicators to make a comprehensive evaluation at the end of each year. The general evaluation model is shown in equation (5).

$$
V=\left|\frac{\sum_{i=1}^{n} q_{i} \times w_{i}}{\operatorname{Max} \sum_{i=1}^{n} q_{i} \times w_{i}+\operatorname{Min} \sum_{i=1}^{n} q_{i} \times w_{i}}-1\right|
$$

In equation (5), $q_{i}$ is the initial value of each indicator, $w_{i}$ is the weight of each indicator.

$\frac{\sum_{i=1}^{n} q_{i} \times w_{i}}{\operatorname{Max} \sum_{i=1}^{n} q_{i} \times w_{i}+\operatorname{Min} \sum_{i=1}^{n} q_{i} \times w_{i}}$ is a value of good degree of the ecological vulnerability (non-vulnerability), which is a normalized ratio and $0 \leq\left|\frac{\sum_{i=1}^{n} q_{i} \times w_{i}}{\operatorname{Max} \sum_{i=1}^{n} q_{i} \times w_{i}+\operatorname{Min} \sum_{i=1}^{n} q_{i} \times w_{i}}\right| \leq 1$ is the proportion of the vulnerability data (proportion to the total extreme vulnerability), obtained after comprehensive evaluation of each indicator. The best eco-situation is the condition that all the existing ecological vulnerabilities have already been evaluated, and all the evaluated vulnerabilities equal to the all extreme vulnerabilities. Namely, its value is 1 , which indicates that though all vulnerabilities have occurred, they did not cause the crises. This is the most favorable ecological environment. However, this ideal situation is generally difficult to happen, so we need to evaluate the degree of vulnerability that is the absolute value of the difference between the good degree and the ideal degree (ideal degree=1). This is the overall ecological vulnerability in a certain period.

\section{Evaluating the changing trend of the ecological vulnerability}

Knowing the changing trends of the ecological vulnerabilities always means a good pre-control because the local governments and other bodies could deal with the changing conditions according to the trend evaluation results. Evaluating the changing trends in fact is an evaluation to the ecological vulnerability change rules within a certain period. The evaluation model is as equation (6):

$$
V c=\frac{v_{t n}-v_{t 0}}{v_{t 0} \times T},\left(n \in R^{+}\right)
$$

In equation (6), $V c$ is the changing degree of vulnerability; $v_{t 0}$ is the value of the ecological vulnerability in the initial evaluation region; $v_{t n}$ is the deadline value of the ecological vulnerability (The deadline is a time till when to implement the evaluation. For example, in a year, the deadline may be December 31, so "deadline value" means the evaluation value get in December 31.); and T is for the intervals in which the vulnerabilities change.

All of the above evaluations could be implemented in the 12 western provinces and two autonomous prefectures by the mined indicators and the data in DW-WEV. The range of the evaluation includes all of the 12 provinces and municipalities of the prefecture-level divisions (a total of 153 units according to the National statistical Yearbook 2009).

\section{Evaluating the Synergy Degrees between the Western Ecological Vulnerabilities and the Performances of the Local Governments}

Evaluating the ecological vulnerabilities aimed at improving the ability of the governments and other bodies to respond promptly to the ecological vulnerabilities and improve the level of the ecological management. However, the basic motivation of the local officials in the western governments to response to the ecological vulnerabilities is that the responding could be an integral part of their performances by which they would be promoted or highly salaried (Chen, Li \& Zhou, 2005). Also, they need to treat equally between the elimination of the ecological vulnerabilities and the incensement of regional GDP. It is sure that high-speed GDP growth in an area certainly leads to the officials' promotion, while protecting the environments does not always help the promotion (Guo, 2007). So protecting the environments and responding to the ecology vulnerabilities depend on how the local officials see the relations between their performances and the ecology vulnerabilities. If they think intervening the vulnerabilities could help to increase their performances, they will make active interventions. Otherwise, they will indulge the vulnerabilities developing in a mass manner. This is actually an eco-based performance concept (performance concept) (Shang, 2011). Consequently, evaluating the synergy degrees between the western ecological vulnerabilities and the performances of the local governments could understand whether the local officials see intervening vulnerabilities as one of their performance sources. Provided they think responding to ecological vulnerabilities could increase their performance, they will intervene the vulnerabilities actively. Or they will let the vulnerabilities run wild. We believe that evaluating the synergy degrees between the western ecological vulnerabilities and the performances of the local governments is an efficient pre-control way to prevent the ecology 
getting worse, because we could alarm the local governments to respond according to the evaluation results. Judged by the synergy degree, the higher the degree, the worse the ecology. Since the high synergy degree means the ecological vulnerabilities become serious and serious when the local governments' performances rise. We could use the coupling model to evaluate the synergy degrees between the western ecological vulnerabilities and the performances of the local governments (see equation (7) and equation (8)).

Set positive numbers $i_{1}, i_{2}, \ldots, i_{m}$ as $\mathrm{m}$ indicators for evaluating the ecological vulnerabilities; set positive numbers $p_{1}, p_{2}, \ldots, p_{n}$ as $\mathrm{n}$ indicators for evaluating the local government performance, then we could obtain the equation (7):

$$
f(i)=\sum_{j=1}^{m} a_{j} i_{j}^{\prime}, g(p)=\sum_{l=1}^{n} b_{l} p_{l}^{\prime},(j=1,2, \ldots, m ; l=1,2, \ldots, n)
$$

Equation (7) is the evaluation function of the overall ecological vulnerability and the local government's overall performance in a particular phase. In the evaluation, $i_{i}^{\prime}\left\{\begin{array}{l}\frac{i_{j}-\beta_{j}}{\alpha_{j}-\beta_{j} i_{j}} \text { is the positive indicators } \\ \frac{\alpha_{j}-i_{j}}{\alpha_{j}-\beta_{j} i_{j}} \text { is the negative indicators }\end{array}, \alpha_{j}\right.$ is the upper value of $i_{j}$; $\beta_{j}$ is the lower value of $i_{j} ; b_{l}$ and $p_{l}$ can be defined in the same way as $\alpha_{j}$ and $i_{i}^{\prime}$. Therefore, the evaluation model of synergy degree $(\mathrm{C})$ between the performance of the local governments and the ecological vulnerability can be obtained, namely equation (8):

$$
C=\sqrt{(f(i) \cdot g(p)) /[f(i)+g(p)]^{2}}
$$

Obviously, $0 \leq C \leq 1$. The maximum value of the synergy degree is $1\left(C_{\max }=1\right)$, and the minimum value is 0 $\left(C_{\min }=0\right)$. Under this model, the greater the synergy degree is, the larger proportion of the ecological vulnerability in the process of obtaining government performance will be. Because the ecological vulnerability is the bad or negative status of ecology, the enhancement of the synergy degree means when the local governments' performances rises, the ecology status become worse.

In evaluating the performances of local governments, a set of indicator system can be developed or we can use various types of scientific indicator system which have already been developed. We suggest that the synergy degree evaluation between the ecological vulnerabilities and the governments' performances can be implemented annually, and the evaluation should include all the 153 prefecture-level governments in the west China. The wellbuilt databases, data warehouses, data marts can be applied for all the evaluations and they could be done in MS SQL, ORACAL and other software.

\section{LOCAL GOVERNMENTS AND OTHER BODIES' TIMELY PRE-CONTROL STRATEGIES IN THE WEST CHINA}

We believe that the coping of ecological vulnerability is essentially the issue of the public management. It requires the governments play the main role, and at the same time, they must absorb other organizations to involve into the ecological management in order to complete the transition of the ecological management from the government to the public. Their coping strategies and measures need to be performed following the results from the evaluation models of equation (4), (5), (6), (8). We have established a strategy matrix in Table 1, and it shows the governments need to make appropriate contingency coping strategies when they are facing the individual vulnerability, the overall vulnerability, the vulnerability trending, and the synergy degree between the

\begin{tabular}{|c|c|c|c|c|c|c|c|}
\hline $\begin{array}{c}\text { Strategies } \\
\text { vulnerability }\end{array}$ & $\begin{array}{c}\text { Main } \\
\text { responding } \\
\text { bodies }\end{array}$ & $\begin{array}{l}\text { Responding } \\
\text { financing }\end{array}$ & $\begin{array}{l}\text { Responding } \\
\text { measures }\end{array}$ & $\begin{array}{l}\text { Implementing } \\
\text { strategies }\end{array}$ & $\begin{array}{c}\text { Evaluating } \\
\text { responding } \\
\text { performance }\end{array}$ & $\begin{array}{l}\text { Responding } \\
\text { accountability }\end{array}$ & $\begin{array}{l}\text { Responding } \\
\text { occasion }\end{array}$ \\
\hline (4) & \multirow{4}{*}{$\begin{array}{c}\text { Local } \\
\text { governments, } \\
\text { environment } \\
\text { departments, } \\
\text { higher level } \\
\text { governments, } \\
\text { social } \\
\text { organizations, } \\
\text { enterprises, } \\
\text { citizens...... }\end{array}$} & \multirow{4}{*}{$\begin{array}{l}\text { Public budget, } \\
\text { emergency } \\
\text { funding, social } \\
\text { contributions, } \\
\text { BOT, BTO, } \\
\text { PPP, Eco } \\
\text { Lottery...... }\end{array}$} & \multirow{4}{*}{$\begin{array}{l}\text { Vegetation } \\
\text { restoration, } \\
\text { timely } \\
\text { intervention, } \\
\text { ecology } \\
\text { compensation, } \\
\text { incorporating } \\
\text { into } \\
\text { performance } \\
\text { evaluation ....... }\end{array}$} & \multirow{4}{*}{$\begin{array}{l}\text { Government } \\
\text { itself, } \\
\text { outsourcing, } \\
\text { establishing } \\
\text { agencies similar } \\
\text { to WMBTR to } \\
\text { implement...... }\end{array}$} & \multirow{4}{*}{$\begin{array}{c}\text { Project } \\
\text { performance } \\
\text { evaluation, } \\
\text { overall } \\
\text { performance } \\
\text { evaluation, } \\
\text { financial } \\
\text { performance } \\
\text { evaluation, } \\
\text { job } \\
\text { performance } \\
\text { evaluation...... }\end{array}$} & \multirow{4}{*}{$\begin{array}{c}\text { Post negative } \\
\text { incentives, } \\
\text { income minus } \\
\text { incentives, hard } \\
\text { budget } \\
\text { constraints, } \\
\text { competitive } \\
\text { organization } \\
\text { building...... }\end{array}$} & \multirow{4}{*}{$\begin{array}{l}\text { Immediate } \\
\text { intervention, } \\
\text { routine ecology } \\
\text { restoration, } \\
\text { routine } \\
\text { maintenance, } \\
\text { interval } \\
\text { involving, } \\
\text { temporary } \\
\text { intervention...... }\end{array}$} \\
\hline (5) & & & & & & & \\
\hline (6) & & & & & & & \\
\hline (8) & & & & & & & \\
\hline
\end{tabular}

Table 1. Matrix of the government coping strategies (Toolbox) 
vulnerabilities and the local governments' performances in a specific period. Here only partial of the strategies have been listed as examples. The specific policies need to be determined according to the results of evaluation of a particular ecological vulnerability. Strategic matrix presented here is a "toolbox" for the western local governments to use selectively.

The responding matrix is constituted in accordance with the environment management principles. It aims to respond to the 4 kinds of vulnerabilities evaluated by equation (4), (5), (6), and (8). In the matrix, "main responding bodies" means in the process to cope with the vulnerabilities, what kind of organization will take actions to respond; "responding financing" means how we can get the money to respond the vulnerabilities; "responding measures" are the measures taken by the respond bodies to intervene and prevent the vulnerabilities; "implementing strategies" point out effective ways to implement the responding policies; "evaluating responding performance" is a feedback tool to know if the responding work is efficient, effective, and economic; "responding accountability" means how the responding bodies admit responsibilities for their inefficient, ineffective, and uneconomic actions; "responding occasion" is the time when the responding bodies begin to involve into the vulnerabilities.

Responding matrix provides a set of strategies similar to the government tool (Been, 2010). These strategies should be used tacitly according to the vulnerability evaluation results. For example, if the local governments respond to a single vulnerability, they have to use equation (4) to evaluate it. Then they could deal with the vulnerability in the light of the evaluation results. During the response, if the evaluation results show that it is only a mild degree of vulnerability, the "main responding bodies" maybe need no more organizations, and the ecology department of a certain local government merely could finish the task to respond the vulnerability.

However, if the evaluation results show the vulnerability is severe, the responding body needs to be expanded. It may need ecology department of the local government, the local government, the higher level government, Red Cross Association, Youth Volunteer Association, and International Relief Organizations to cooperate on responding. Raising the responding money is similar to decide the responding bodies. If the evaluation results show the vulnerability is mild, it may only need to properly allocate annual public budget. But if the results indicate it is a severe vulnerability, we have to apply the emergency funding from the higher level governments, encourage citizens to contribute, use BOT, BTO, or even issue ecological lottery for financing. Selecting the specific coping strategies for "responding measures", "implementing strategies", "evaluating responding performance", "responding accountability", and "responding occasion" is also similar to the contingency approach of selecting "main body" or "responding financing". The selection needs to choose the right tool based on the results of the evaluations. We could choose proper strategies from the toolbox to make responding actions. Of course, the matrix (toolbox) in Table 1 provides only the most common tools. In the actual response, we also can "manufacture", "create", and develop more tools to respond the vulnerability efficiently, effectively, and economically.

\section{DISCUSSION}

In recent years, ecological crises caused by ecological vulnerabilities in western China occur more and more frequently, and the crises even begin to spread to other districts. It is worth the theorists and practitioners alert. Seen from the current researches, the scholars pay no enough attention to explore how to pre-control the western ecological vulnerabilities by evaluating them.

In this study, we firstly develop the PSR model based on the actual situation of the ecological vulnerabilities in the western China. On the basis of the new PSR model, we propose a pre-control model which mainly emphasizes evaluating the western vulnerabilities and the synergy degrees between the western ecological vulnerabilities and the performances of the local governments. Under the guidance of the evaluating results, the local governments and other organizations could respond efficiently, effectively, and economically. Although a lot of work has been done, there still exist a great number of problems to be solved so that the pre-control work could be done smoothly.

Firstly, the western China ecological vulnerability evaluation database should be constructed. Now, there is lots of western vulnerability data scattered in varied databases such as GIS, GPS, GOOGLE-EARTH, and EIS, but the data has not been used efficiently. In the future, we could use "big data" technologies and data mining skills to stride over the gap between these scattered databases to build a "western China ecological vulnerability evaluation database" that is composed by a series of sub-databases.

Secondly, we should develop proper western vulnerability evaluation value. In China, from top to the bottom, there exists "developmentalism" (García, 2011). Judged by the value of "developmentalism", only GDP growth, tax growth, expressway growth, and so on are useful to the governments of varied levels. The developmentalism pays no attention to protecting the ecology unless doing so could lead to "growths" mentioned above. But by and large, protecting the environments takes a great amount of public money, which will affect the governments developing economy. So the governments always neglect involving into the ecological problems and pre-controlling the ecological vulnerabilities. In the future, we should establish a sustainable developing value in western China. 
Under the new value, the local governments are needed to treat economy developing and ecology protecting equally.

Thirdly, other the theorists or the practitioners could design a set of scientific ecological vulnerability evaluation indicators. From the perspective of the evaluation science, the indicator system is the key to uncover the black box of organization and management. In the evaluation of the ecological vulnerability, the indicator system is the key to open the vulnerability state of the "ecological black box". Although there have appeared some explorations in this area, they still cannot satisfy the needs to measure the western ecological vulnerabilities.

Fourthly, evaluating the ecological vulnerabilities scientifically demands reliable evidence data. According to the general process of the evaluation science, an efficient evaluation needs useful and representative data to support the indicators (Hofbauer \& Sigmund, 1988). To some extent, the quality of ecological vulnerability evaluation depends on the quality of evidence data. In the coming time, we could develop new methods to detect, select, and make use of the vulnerability evidence data from thousands of scattered data in western China.

Fifthly, the effective path to implement the vulnerability evaluation could be explored. This involves choosing the proper evaluating cites, deciding the evaluating time, and determining the evaluation flows.

Eventually, applying the evaluation results to pre-control ecological crises would be emphasized. Unlike the evaluations in other areas, ecological vulnerability evaluation pays special attention to the individual indicators that may uncover some special ecological crises. For example, an indicator to evaluate landscape changing may imply an earthquake which belongs to ecological crisis, and the governments of varied levels and other responding bodies should take efficient measures to avoid the damages might caused by the would-be earthquake in advance. This is really an ecological crisis management based on the evaluation results. Such pre-control work should be done widely and efficiently in the future.

\section{ACKNOWLEDGEMENTS}

The Research supported by National Foundation of Philosophy and Social Science of China (Granted No. 14BGL115), Foundation of Humanities and Social Science of Chinese Ministry of Education (Granted No. 13YJAZH076), Project of Collaborative Innovation Center for New-type Urbanization and Social Governace of Jiangsu Province, and Project of Outstanding Innovation Team of Philosophy and Social sciences in Jiangsu Universities (granted No. 2015ZSTD010).

\section{REFERENCES}

Been, V. (2010). Community Benefits Agreements: A New Local Government Tool or Another Variation on the Exactions Theme? The University of Chicago Law Review, 77(1), 5-35.

Bennett, M. T. (2008). China's sloping land conversion program: Institutional innovation or business as usual? Ecological Economics, (65), 700-712.

Chen, Y., Li, H., \& Zhou, L. A. (2005). Relative performance evaluation and the turnover of provincial leaders in China. Economics Letters, 88(3), 421-425.

García, C. (2011). Grid-connected renewable energy in China: Policies and institutions under gradualism, developmentalism, and socialism. Energy Policy, 39(12), 8046-8050.

Guo, G. (2007). Retrospective economic accountability under authoritarianism: evidence from China. Political Research Quarterly, 60(3), 378-390.

Hartigan, J. A. (1975). Clustering algorithms. New York: Wiley.

Hofbauer, J., \& Sigmund, K. (1988). The theory of evolution and dynamical systems: mathematical aspects of selection. Cambridge: Cambridge University Press.

Jim, C. Y., \& Chen, W. Y. (2009). Ecosystem services and valuation of urban forests in China. Cities, 26(4), 187-194.

Kai, C., \& Haokai, L. (2016). Factors Affecting Consumers' Green Commuting. Eurasia Journal of Mathematics, Science $\mathcal{E}$ Technology Education, 12(3).

Li, T., Shilling, F., Thorne, J., Li, F., Schott, H., Boynton, R., \& Berry, A. M. (2010). Fragmentation of China's landscape by roads and urban areas. Landscape Ecology, 25(6), 839-853.

Liu, Q., Ge, X., Chen, W., \& Columbus, J. T. (2009). Grass (Poaceae) richness patterns across China's nature reserves. Plant ecology, 201(2), 531-551.

Magretta, J. Managing in the New Economy (ed.). Boston Cambridge: Harvard Business Press, 1999: Introduction VIII.

Melick, D., Yang, X., \& Xu, J. (2007). Seeing the wood for the trees: How conservation policies can place greater pressure on village forests in southwest China. Biodiversity and Conservation, 16(6), 1959-1971. 
Michalk, D. L., Limin, H., \& Kemp, D., et al. (2010). Redesigning livestock systems to improve household income and reduce stocking rates in China's western grasslands. In Towards Sustainable Use of Rangelands in NorthWest China. Springer Science \& Business Media.

National Disaster Reduction Center of the Ministry of Civil Affairs (NDRCMCA). (2009). The top ten ecological incidents. Retrieved from http://www.mlr.gov.cn/zt/dqr/40dqr/wcdz/200903/t20090330_117289.htm.

New, T., \& Xie, Z. (2008). Impacts of large dams on riparian vegetation: Applying global experience to the case of China's Three Gorges Dam. Biodiversity and Conservation, 17(13), 3149-3163.

Pimentel, D., Cooperstein, S., \& Randell, H., et al. (2007). Ecology of increasing diseases: Population growth and environmental degradation. Human Ecology, 35(6), 653-668.

Prokop, P., Medina-Jerez, W., Coleman, J., Fančovičová, J., Özel, M., \& Fedor, P. (2016). Tolerance of Frogs among High School Students: Influences of Disgust and Culture. Eurasia Journal of Mathematics, Science E Technology Education, 12(6), 1499-1505.

Rapport, D. J., Costanza, R., \& McMichael, A. J. (1998). Assessing ecosystem health. Trends in Ecology E Evolution, 13(10), 397-402.

Rapport, D., \& Friend, A. (1979). Towards a comprehensive framework for environmental statistics: A stressresponse approach, Statistics Canada, 11(5), 87.

Shang, H. (2013). Government performance evaluation indicators designing based on data-mining: A research in four municipal governments. Beijing: Economy and Management Press.

Shang, H. P. (2011). Ecology vulnerability evaluation for west China. China Soft Science, (9), 122-133. (in Chinese).

Squires, V., Hua, L., Zhang, D., \& Li, G. (Eds.). (2010). Towards sustainable use of rangelands in North-West China. Springer Science \& Business Media.

Tilt, B. (2008). Smallholders and the 'household responsibility system': Adapting to institutional change in Chinese agriculture. Human Ecology, 36(2), 189-199.

Uchida, E., Xu, J., \& Rozelle, S. (2005). Grain for green: Cost-effectiveness and sustainability of China's conservation set-aside program. Land Economics, 81(2), 247-264.

Wang, X., Lu, C., Fang, J., \& Shen, Y. (2007). Implications for development of grain-for-green policy based on cropland suitability evaluation in desertification-affected north China. Land Use Policy, 24(2), 417-424.

Weihrich, H., \& Koontz, H. (2005). Management: A global perspective. Singapore: McGraw-Hill.

Williams, D. M. (1997). Patchwork, pastoralists, and perception: Dune sand as a valued resource among herders of Inner Mongolia. Human Ecology, 25(2), 297-317.

Wong, F. K., Lacap, D. C., Lau, M. C., Aitchison, J. C., Cowan, D. A., \& Pointing, S. B. (2010). Hypolithic microbial community of quartz pavement in the high-altitude tundra of central Tibet. Microbial ecology, 60(4), 730-739.

Yamaguchi, T. (2011). Transition of mountain pastoralism: An agrodiversity analysis of the livestock population and herding strategies in southeast Tibet, China. Human Ecology, 39(2), 141-154.

Yang, W. G. (2010). The disasters burst coincidently. The Beijing News, 2010-8-23. (in Chinese).

Ye, K. S. (2010). Heavy rains rob 29 lives in Chongqing. Guangzhou Daily, 2010-5-7, 5th edition. (in Chinese).

Yuan, J., Muyi, K., Shuo, L., Lianshu, T., \& Mingde, L. (2000). A Study on the Vegetation in the East Side of Helan Mountain. Plant Ecology, (149), 119-130.

Zhang, J. Y., Su, W. C., \& Zhang, F. T. (2011). Regional land ecological security evaluation in the case of Chongqing Three Gorges Reservoir ecological economy area based on the PSR model. China Environmental Science, 31(6), 1039-1044.

Zhang, J., Pan, X., Gao, Z., Shi, Q., \& Lv, G. (2006). Carbon uptake and change in net primary productivity of oasisdesert ecosystem in arid western China with remote sensing technique. Journal of Geographical Sciences, 16(3), 315-325.

Zhao, G., \& Shao, GF. (2006). Logging restrictions in China: A turning point for forest sustainability. Journal of Forestry, (100), 34-37.

Zhou, L. (2010). We are still in the key period of fighting against ecological rises. Retrieved from http://www.eeo.com.cn/Politics/by_region/2010/07/21/176152.shtml. (in Chinese).

\section{http://www.ejmste.com}

